Recebido em 03/2019. Aceito para publicação em 09/2019.

\title{
ANÁLISE DOS ALÉRGENOS DECLARADOS EM CARDÁPIOS DE RESTAURANTES EM SHOPPINGS
}

ANALYSIS OF DECLARED ALLERGENS ON MENUS OF MALLS RESTAURANTS

\author{
Mariana Cerne Aufieri ${ }^{1}$ \\ Júlia Queiroz Reis Boccia ${ }^{2}$ \\ Silvia Elise Rodrigues Henrique ${ }^{3}$ \\ Mônica Glória Neumann Spinelli ${ }^{4}$
}

Resumo: Atualmente, a população tem menos tempo para realizar sua refeição em casa, por isso a alta demanda em restaurante autosserviço, "fast foods" e outros localizados em "shoppings". De acordo com o Art. 6 da Lei no 8.078, de 11 de setembro de 1990, é um direito básico do consumidor a informação adequada e clara sobre os ingredientes e os riscos que determinado alimento apresenta, porém, grande parte dos restaurantes não assume a responsabilidade de apresentar produtos com informações necessárias sobre os possíveis ingredientes causadores de alergias. O presente estudo teve como objetivo quantificar restaurantes que tenham a proposta de apresentação de alérgenos nos cardápios, analisar quais os declarados e como foi feita essa inserção. A pesquisa foi realizada em quatro "shoppings" da região da Avenida Paulista, onde foram levantados os restaurantes presentes na praça de alimentação, classificando-os em dois grupos, segundo a declaração ou não dos alérgenos em seus cardápios. Para cada "shopping", foram sorteados dois restaurantes, um de cada grupo, que responderam dois questionários elaborados pelos Pesquisadores Responsáveis. Do total de restaurantes analisados, $13 \%$ declaravam os alérgenos em seus cardápios e $87 \%$ não declaravam. Dos que declaravam, foi identificada a presença de glúten e traços de soja, peixe, ovo e trigo, através de símbolos e escrita. Conclui-se que os restaurantes de "shoppings", em sua maioria, não possuem indicação de alérgenos em seus cardápios, e os que possuem, declaram apenas a presença de glúten.

Palavras-chave: Alérgenos; restaurantes; cardápios; alergia alimentar.

Abstract: Currently, the population has less time to prepare their meal at home, therefore the high demand in "self-service" restaurants, fast foods and others located in malls. According to Art. 6 of Law No. 8,078, of September 11, 1990, it is a basic right of the consumer to have adequate and clear information about the ingredients and the risks that a particular food presents. However, most restaurants do not assume the responsibility to present products with necessary information about the possible ingredients that may cause allergies. The present study aimed to identify restaurants that have the proposal of presenting allergens in the menus, to analyze which are declared and how this insertion was made. The research was carried out in four malls in the Paulista Avenue area, where the restaurants in the food court were surveyed, classifying them into two groups according to the statement or not of the allergens in their menus. For each mall, two restaurants were drawn, one from each group, which answered two questionnaires prepared by the Responsible Researchers. Of the total of restaurants analyzed, 13\% declared allergens on their menus and $87 \%$ did not declare. Of those who declared, the presence of gluten was identified, as well as soy, fish, egg and wheat traces, by writing and symbols. It is concluded that mall restaurants, for the most part, have no indication of allergens in their menus, and those who have it, only

\footnotetext{
1 Graduanda em Nutrição, Universidade Presbiteriana Mackenzie, Brasil. E-mail: marianaaufieri@gmail.com.

2 Graduanda em Nutrição, Universidade Presbiteriana Mackenzie, Brasil. E-mail: julia.boccia98@gmail.com.

${ }^{3}$ Graduanda em Nutrição, Universidade Presbiteriana Mackenzie, Brasil. E-mail: silviaelise@hotmail.com.

${ }^{4}$ Nutricionista, mestre e doutora em Saúde Pública (área de concentração - nutrição) pela Faculdade de Saúde Pública da Universidade de São Paulo (USP), professora adjunta do curso de nutrição da Universidade Presbiteriana Mackenzie, Brasil. E-mail: monica.spinelli@mackenzie.br.
} 
declare the presence of gluten.

Keywords: Allergens; restaurants; menus; food allergy.

\section{INTRODUÇÃO}

Solé et al. (2018a), no Consenso Brasileiro sobre Alergia Alimentar, definem a alergia alimentar como uma doença de resposta imunológica de hipersensibilidade que ocorre após a ingestão ou contato com um determinado alimento, chamado de alérgeno. Este é definido como qualquer substância que estimula uma resposta de hipersensibilidade, sendo representado por glicoproteínas hidrossolúveis, porém, há poucas exceções frente a este conceito que são os compostos por carboidratos, como a fucose, xilose e alfa-gal. As reações alérgicas podem ser imunológicas ou não imunológicas, ou seja, os mecanismos imunológicos podem ser mediados por anticorpos lgE ou não.

É estimado que um quarto da população mundial enfrente alguma reação adversa a um determinado alimento, no mínimo, durante a vida (BURKS; JAMES; EIGENMANN, 2011). Segundo Oliveira et al. (2018), "estima-se que a prevalência da alergia alimentar seja de 6 a $8 \%$ em crianças menores de três anos e cerca de 2 a $4 \%$ em adultos". O grau da alergia vai depender do processamento do alimento e da sua digestão, assim como do perfil do indivíduo. Solé et al. (2018b) afirmam que a maioria das alergias alimentares ocorre após a ingestão de leite de vaca, ovo, soja, trigo, amendoim, peixes e crustáceos. Os possíveis fatores de risco para a alergia alimentar são a predisposição genética, fatores ambientais, culturais e comportamentais.

Matricardi et al. (2016) demostraram que o alimento é capaz de reagir quando ingerido ou em contato com a pele ou com o trato respiratório; através da reatividade cruzada, há produção de IgE específica, tendo contato direto com o alimento ou não, sendo um alérgeno inalável (SOLÉ et al., 2018a).

Segundo a Food Allergy Research \& Education - FARE (2018), dos Estados Unidos, a alergia alimentar não tem uma cura, apenas medidas que controlam as inflamações, como a restrição aos alérgenos e o reconhecimento precoce das reações. A FARE afirma que cerca de quinze milhões de americanos são afetados por alguma alergia alimentar e também que 170 alimentos foram reportados por causarem reações alérgicas (FOOD ALLERGY...., 2018). Um estudo de Gupta, Holdford e Bilaver (2013) chegou à conclusão de que os gastos de uma criança norte americana alérgica chegavam a $\$ 4184$ por ano enquanto visitas clínicas, emergências e hospitalização geravam custos em torno de $\$ 4,3$ bilhões por ano.

A maioria dos indivíduos ingere cerca de três refeições ao dia, fazendo com que o alimento esteja envolvido em uma grande variedade de distúrbios. A prevalência de doenças alérgicas tem aumentado nas últimas décadas e a alergia alimentar é um importante fator responsável por esse aumento. Em alguns casos, a alergia alimentar pode causar sintomas graves ou até mesmo uma reação com risco de vida - 
conhecida como anafilaxia (FERREIRA; PINTO, 2012). Segundo Solé et al. (2018b), as reações mais comuns que surgem após a exposição ao alimento ou seu consumo, relacionadas ao mecanismo imunológico mediado por $\lg \mathrm{E}$, são os gastrointestinais, as respiratórias, sistêmicas e cutâneas.

A Doença Celíaca (DC) é uma enteropatia crônica do intestino delgado, autoimune, que é estimulada pela exposição ao glúten (principal fração proteica presente no trigo, centeio e cevada) em indivíduos que tem essa sensibilidade (LUDVIGSSON et al., 2013; RUBIO-TAPIA et al., 2013). Segundo Sdepanian, de Moraes e Fagundes (1999), a falta de conhecimento sobre a doença e o difícil acesso aos meios diagnósticos diminuem as possibilidades de tratamento adequado e consequentemente a melhoria clínica. Os estudos revelaram que o problema atinge todas as idades, mas implica principalmente crianças de 6 meses a 5 anos. Também foi visto uma frequência grande entre mulheres, na fração de duas mulheres para cada homem.

A alergia ao amendoim é tipicamente mediada por IgE com manifestação clínica ocorrendo de minutos até duas horas após a ingestão do alimento. Estudo americano aponta ser de 24 meses a média de idade da primeira reação ao amendoim, sendo que mais de $70 \%$ delas ocorre já na primeira ingestão conhecida do alimento (OLIVEIRA et al., 2018; SOLÉ et al., 2018b).

A alergia ao ovo é uma das mais comuns no mundo inteiro, geralmente some até os 10 anos de idade, mas pode insistir em algumas pessoas e tem sido associada à anafilaxia, enterocolite, dermatite atópica e esofagite eosinofílica. Crianças que têm alergia a ovo têm grande possibilidade de ter de amendoim também (ALERGIA..., 2016).

A alergia ao trigo é outro dos tipos de alergias mais comuns em crianças. Esta alergia atinge $3 \%$ da população infantil dos Estados Unidos da América. Estas proteínas são resistentes a altas temperaturas, estando presentes, independentemente de o alimento ser ou não cozido, desencadeando sempre alergia (CIANFERONI, 2016).

Hoje, a rotina corrida da população faz com que não haja mais o tempo necessário de preparar o almoço em casa, por isso o surgimento contínuo de restaurantes autosserviço e a procura por refeições práticas em fast foods, shoppings, entre outros locais de alimentação. Nessas unidades de alimentação coletiva, os alimentos são preparados, com exceção de restaurantes específicos para determinados tipos de alimentação, com ingredientes mais acessíveis e práticos, como o trigo, leite e ovos, alérgenos importantes para a sensibilidade (FERNANDES et al., 2017).

Os estabelecimentos que demonstram um maior risco aos alérgicos são os restaurantes com autosserviço, sorveterias e padarias, devido ao maior 
compartilhamento dos utensílios, o que favorece a contaminação cruzada (PÁDUA et al., 2016).

De acordo com o Art. 6ํ da Lei ํㅜ 8.078, de 11 de setembro de 1990 (BRASIL, 1990), é um direito básico do consumidor "a informação adequada e clara sobre os diferentes produtos e serviços, com especificação correta de quantidade, características, composição, qualidade, tributos incidentes e preço, bem como sobre os riscos que apresentem". Pode-se dizer que uma grande parte dos restaurantes não se encontram ajustados a esta lei, já que não assumem a responsabilidade de apresentar produtos com informações necessárias sobre os possíveis ingredientes que podem causar alergias nos consumidores. Após uma intensa manifestação da sociedade, a Agência Nacional de Vigilância Sanitária (ANVISA, 2018) declarou ser obrigatória a presença de alérgenos na rotulagem dos alimentos, assim como a possibilidade de conter contaminação cruzada, porém, essa obrigatoriedade ainda não se estende aos cardápios de restaurantes.

\section{OBJETIVOS}

\subsection{Objetivo geral}

Quantificar restaurantes que tenham a proposta de apresentação de alérgenos nos cardápios.

\subsection{Objetivos específicos}

Analisar quais destes alérgenos são declarados e como são identificados.

\section{MATERIAL E MÉTODO}

A pesquisa foi realizada em quatro (4) shoppings da região da Avenida Paulista, por ser um polo de comércio e serviços e pelo número de shoppings nesta avenida, visando buscar informações sobre alérgenos nos cardápios dos restaurantes presentes na praça de alimentação destes locais. Foram abordados todos os restaurantes, com exceção de quiosques e restaurantes que não possuíam um cardápio definido, e a classificação em dois grupos: declarados e não declarados, segundo a presença ou não de indicação dos alérgenos em seus cardápios. Dentro do grupo "não declarados", houve três subgrupos: "tabela" (denominação para aqueles que possuíam uma tabela à parte indicando os possíveis alérgenos nas preparações), "cardápio próprio" (para os restaurantes que possuíam um cardápio especial livre de alérgenos) e "nada" (para aqueles que não tinham nenhuma identificação ou algo que pudesse ajudar o consumidor na escolha da preparação livre de alérgenos).

Foram elaborados dois questionários pelos Pesquisadores Responsáveis 
(Quadro 1 e Quadro 2), porém, apenas um seria aplicado aos gestores ou funcionários dos restaurantes que se disponibilizaram a responder, já que os questionários diferiam, sendo um para o grupo "declarados" e o outro, para os "não declarados". Para cada shopping, foi sorteado um restaurante de cada grupo, totalizando dois restaurantes por shopping. O sorteio não levou em consideração os subgrupos "tabela", "cardápio próprio" ou "nada" daqueles que não declaravam.

Cada shopping recebeu um número (de 1 a 4), e a identificação dos restaurantes foi feita por meio do nome "declarado" e "não declarado". A identificação do restaurante, como sendo de rede (franquia) ou não, também foi feita, para a análise posterior. Foram considerados restaurantes de rede todos os estabelecimentos (fast food ou restaurantes convencionais) que, embora situados em diferentes shoppings, pertencem a um mesmo grupo empresarial.

Quadro 1 - Questionário para os restaurantes do grupo declarados. São Paulo, 2018.

\section{Alérgenos informados:}

( ) glúten ( ) amendoim ( ) ovo ( ) leite de vaca ( ) soja ( ) trigo ( ) camarão ( ) outros:

1. Como é feita a identificação:

2. Qual é a procura e a demanda desses alimentos?

3. O que incentivou à mudança no cardápio?

4. Os garçons, durante a distribuição dos pratos, possuem conhecimento:

( ) que o prato precisa ser entregue imediatamente após a finalização do preparo

( ) da necessidade da separação das bandejas e utensílios

( ) para responder o consumidor em caso de dúvidas sobre a preparação Observações:

5. Durante o pré preparo e preparo dos pratos livres de alérgenos, há:

( ) separação dos óleos para fritura

( ) a não exposição a possíveis alérgenos

( ) área separada dos demais pratos

6. ( ) utensilios próprios Observações:

Quadro 2 - Questionário para os restaurantes do grupo não declarados. São Paulo, 2018.

1. Vocês têm clientes que solicitam informações sobre os ingredientes devido à alergia ou restrições alimentares? ( ) sim ( ) não

2. Os funcionários recebem algum tipo de treinamento e/ou instruções a respeito de alérgenos na refeição? ( ) sim ( ) não

Se sim, quais funcionários recebem e qual o tipo de treinamento/instrução?

3. Qual a demanda de pratos livres de alérgenos? () não existe () pouco frequente () muito frequente

4. Seria um diferencial para o restaurante atender a esta demanda? ( ) sim ( ) não

5. Acha que teria possibilidade de atender a esta demanda? ( ) $\operatorname{sim}($ ) não 
Esse estudo faz parte de um projeto maior intitulado "Qualidade em Serviços de Alimentação" aprovado pelo CAEE48483015.7.0000.0084. A pesquisa cumpriu todos os requisitos éticos da Resolução 466, que trata da pesquisa com seres humanos. Todos os entrevistados, ao serem abordados, foram esclarecidos sobre os objetivos da pesquisa. Foi lhes assegurado o sigilo e o direito de participar ou não da pesquisa e de poderem desistir a qualquer momento, sem nenhum prejuízo. Aos que concordaram foi solicitada a assinatura do Termo de Consentimento Livre e Esclarecido.

\section{DESENVOLVIMENTO}

\subsection{Resultados}

Foram analisados 110 restaurantes, com um total de 7 gestores questionados, 4 sendo de restaurantes classificados "não declarados" e 3 sendo dos "declarados". Essa diferença dos gestores deve-se ao fato de que em um dos shoppings não houve nenhum restaurante com declaração de alérgenos, portanto, não foi realizada a entrevista.

Tabela 1 - Identificação de alérgenos nos cardápios em relação ao número de restaurantes. São Paulo, 2018.

\begin{tabular}{lcc}
\hline Grupo & Restaurantes & $\%$ \\
\hline Declarados & 14 & 13 \\
Não declarados & 96 & 87 \\
\hline Total & 110 & 100 \\
\hline
\end{tabular}

Tabela 2 - Distribuição do número de restaurantes "não declarados" segundo os shoppings pesquisados e dos meios disponíveis de informação ao consumidor sobre as preparações nestes restaurantes. São Paulo, 2018.

\begin{tabular}{cccccc}
\hline Shopping & Restaurantes & Tabela & Cardápio próprio & Nada & Total (\%) \\
\hline 1 & 34 & $6(18 \%)$ & $1(3 \%)$ & $27(79 \%)$ & 100 \\
2 & 21 & $2(10 \%)$ & $0(0 \%)$ & $19(90 \%)$ & 100 \\
3 & 16 & $4(25 \%)$ & $0(0 \%)$ & $12(75 \%)$ & 100 \\
4 & 25 & $5(20 \%)$ & $1(4 \%)$ & $19(76 \%)$ & 100 \\
\hline Total & 96 & $17(18 \%)$ & $2(2 \%)$ & $77(80 \%)$ & 100 \\
\hline
\end{tabular}

Dos restaurantes "não declarados", 18\% disponibilizavam tabelas com informações dos ingredientes das preparações, 2\% tinham um cardápio próprio para consumidores alérgicos ao glúten, e $80 \%$ não disponibilizavam nenhuma das duas opções. 
A Tabela 2 mostra que a maioria dos restaurantes pertenceu ao subgrupo "nada" (80\%). A falta de conhecimento dos colaboradores pode prejudicar na hora de esclarecer o consumidor, já que funcionários de alguns restaurantes de rede (franquia) afirmaram não haver nada que pudesse auxiliá-los. Observaram-se diferenças entre os estabelecimentos de rede, não havendo informação em alguns e em outros a presença de uma tabela auxiliar.

Os dados não foram modificados e estão de acordo com o que foi declarado na hora da visualização do cardápio e classificação do restaurante, a fim de representar a realidade de indivíduos alérgicos na hora de obter informações.

Em relação aos restaurantes entrevistados com alérgenos "não declarados", todos afirmaram que têm clientes que buscam informações sobre os ingredientes que compõem as preparações e que a demanda desses pratos livres de alérgenos é pouco frequente, já que não há a identificação em seus cardápios. Todos os gestores entrevistados acreditam que seria um diferencial a inclusão das identificações, três (75\%) que haveria a possibilidade de prestar esse atendimento, e um restaurante (25\%) não conseguiria, pois afirmou que a ação teria que vir da rede, e não de sua loja específica.

Tabela 3 - Identificação de alérgenos nos cardápios dos restaurantes "declarados" dos shoppings. São Paulo, 2018.

\begin{tabular}{cccccc}
\hline \multicolumn{9}{c}{ Alérgenos declarados } & \multicolumn{2}{c}{ Identificação } \\
$\begin{array}{c}\text { Shopping } \\
(\mathrm{n})\end{array}$ & $\begin{array}{c}\text { Restaurantes } \\
\text { Traços de soja, }\end{array}$ & $\begin{array}{c}\text { Glúten } \\
(\mathrm{n})\end{array}$ & $\begin{array}{c}\text { peixe, ovo e trigo } \\
(\mathrm{n})\end{array}$ & $\begin{array}{c}\text { Símbolos } \\
(\mathrm{n})\end{array}$ & $\begin{array}{c}\text { Escrito } \\
(\mathrm{n})\end{array}$ \\
\hline 1 & 2 & 2 & 0 & 2 & 0 \\
2 & 0 & - & - & - & - \\
3 & 6 & 4 & 2 & 3 & 3 \\
4 & 6 & 5 & 1 & 5 & 1 \\
\hline Total & 14 & $11(79 \%)$ & $3(21 \%)$ & $10(71 \%)$ & $4(29 \%)$ \\
\hline
\end{tabular}

Nos restaurantes "não declarados" cujos gestores ou funcionários foram questionados, foi citado que apenas os cozinheiros recebiam treinamento especial para preparar corretamente os pratos, porém afirmaram que, dependendo do pedido do consumidor, o cozinheiro apenas retirava o ingrediente na hora da preparação, não se preocupando em possíveis contaminações cruzadas.

Os restaurantes que declaravam alérgenos em seus cardápios representaram a minoria neste estudo, o que já era esperado. Destes, todos afirmaram que a mudança teve iniciativa pela rede ou pelo próprio restaurante. Por mais que alguns funcionários não soubessem responder ao consumidor devido à falta de preparo e conhecimento, durante a fritura os óleos e os utensílios eram separados.

Os gestores entrevistados, com exceção de um, acreditam que seria um 
diferencial atender às questões de identificação de alérgenos no cardápio e poderiam atender a essa demanda. Observou-se que entre a maioria dos funcionários, em ambos os grupos, principalmente garçons e caixas, havia desconhecimento sobre a necessidade de entrega imediata do alimento após o preparo, separação das bandejas e da separação de áreas. Acresce-se a isso o fato de não terem capacidade de tirar dúvidas de consumidores sobre o assunto. Gestores do grupo "não declarados" informaram que, dependendo do pedido do consumidor, o cozinheiro apenas retira o ingrediente alérgeno para a preparação, mesmo após afirmar que esse funcionário recebe um treinamento especial para a preparação correta desses pratos.

\subsection{Discussão}

Este estudo, embora limitado pelo tamanho amostral, tem sua importância ao mostrar que os restaurantes ainda não perceberam a necessidade de incluírem as pessoas necessitadas de atenção na hora das suas refeições. Nos 110 restaurantes estudados neste trabalho, observou-se que a maior parte dos colaboradores no restaurante não estão habilitados a orientar os clientes com relação aos possíveis alérgenos no cardápio.

Estudo realizado por Radke et al. (2014), nos Estados Unidos, com 278 restaurantes, apresentou resultado semelhante, no qual a minoria dos trabalhadores gerentes, cozinheiros e garçons - recebia treinamento especial para o atendimento de pessoas alérgicas, sugerindo que este aspecto se repete em vários países e deve receber maior atenção neste setor.

O Manual de Alergia Alimentar na Restauração de Portugal (PÁDUA et al., 2016) afirma que os funcionários precisam ter a consciência de que a alergia alimentar se trata de uma doença e não de uma preferência alimentar, como o veganismo, por exemplo. Por isso, devem responder corretamente às perguntas dos consumidores, conhecer os pratos, informar sobre os métodos de preparação e os ingredientes utilizados e serem compreensivos em relação ao anseio do alérgico e de sua família. Durante o serviço da refeição, esta não pode ficar esperando pelo garçom na cozinha e não pode ser transportada até a mesa com outros pratos, devido à possibilidade de haver uma contaminação cruzada nesse período de tempo. A Food Allergy Research \& Education (FARE) (2018) recomenda a todos os restaurantes que mostrem uma lista contendo todos os ingredientes do alimento, quando solicitado pelo cliente.

Observa-se na Tabela 2 que a maioria dos restaurantes não tem nenhum método de declarar os alérgenos e na Tabela 3 , que os que declaram ainda o fazem de maneira tímida. Em outras partes do mundo já há uma mobilização para que os cuidados com relação aos alérgenos nos alimentos sejam mais efetivos, como no Reino Unido, por meio da Food Standards Agency (FSA) (2014), que elaborou um documento referente à nova legislação que obriga as empresas de alimentos a 
indicarem a presença de alérgenos no alimento, sendo feita tanto no cardápio de um restaurante quanto na embalagem de uma padaria, por exemplo. Os 14 alérgenos que devem ser obrigatoriamente citados são: aipo, glúten, crustáceos, ovos, peixe, tremoço, leite, moluscos, mostarda, nozes, amendoim, gergelim, soja e o dióxido de enxofre.

É possível observar a importância de atender um público cada vez mais diversificado, incluindo os que apresentam problemas alérgicos, considerando-se o aumento da demanda de refeições em restaurantes, pela falta de tempo das pessoas (SICHERER; SAMPSON, 2014; COCCO et al., 2007; SOLÉ et al., 2018b).

Segundo Oliveira et al. (2018), como grande parte da sociedade apresenta certa intolerância ou alergia diante a algum alérgeno, facilitar a refeição dessas pessoas seria uma forma de inclusão e economia de tempo.

A falta de estudos sobre este tema chama a atenção, por se tratar de uma realidade que pode trazer consequências prejudiciais à saúde de certos indivíduos.

\section{CONCLUSÃO}

Os restaurantes de shoppings, em sua maioria, não possuem indicação de alérgenos em seus cardápios, e os que possuem, declaram apenas a presença de glúten através de símbolos e escritas. Trigo, ovo, peixe e soja apareceram por escrito como "pode haver traços de", no final dos cardápios. Os demais alérgenos não foram citados em nenhum momento.

Todos os restaurantes que não declaravam diziam ser pouco frequente a demanda por produtos com algum tipo de ingrediente possível de causar alergia.

Devem ser realizadas mais pesquisas a fim de mostrar a importância de implantar meios de auxílio ao consumidor na hora da escolha de sua refeição, assim como treinar corretamente todos os funcionários sobre as possíveis reações e de manusear processos livres de contaminação cruzada.

\section{REFERÊNCIAS}

ALERGIA ao ovo e leite. Laboratório Duarte, n. 6, p. 1-2, 2016. Disponível em: <http://laboratorioduarte2014.masterix2.com.br/uploads/laboratorio_duarte_2014/arqui vos/lab-com-alergia-ao-ovo-e-ao-leite-junho-2016.pdf>. Acesso em: 23 set. 2018.

ANVISA. Rotulagem de alimentos alergênicos. 2018. Disponível em: <http://www.portal.anvisa.org.br>. Acesso em: 23 set. 2018.

BRASIL. Constituição Federal de. Lei no. 8.078, de 11 de setembro de 1990: Dispõe sobre a proteção do consumidor e dá outras providências. Diário Oficial da União, 
Brasília, 1990.

BURKS, W.; JAMES, J.; EIGENMANN, P. Food allergy. 1 ed. United States: Elsevier Health Sciences, 2011.

CIANFERONI, A. Wheat allergy: diagnosis and management. Journal of Asthma and Allergy, v. 9, p.13-25, 2016.

COCCO, R. R. et al. Abordagem laboratorial no diagnóstico da alergia alimentar. Rev. Paul. Pediatr., v. 25, n. 3, p. 258-265, 2007.

FERNANDES, R. de C. de S. et al. Proposta educativa para o avanço nas escolhas alimentares de alérgicos em serviços de alimentação: relato de projeto. $\mathbf{R e v}$ da Universidade Vale do Rio Verde, v. 15, n. 1, p. 842-850, 2017.

FERREIRA, J. M. S.; PINTO, F. M. H. Alergia alimentar: definições, epidemiologia e imunopatogênese. Rev Bras Nutr Clin, v. 27, n. 3, p. 193-198, 2012.

FOOD ALLERGY RESEARCH \& EDUCATION (FARE). Food Allergy Facts and Statistics for the U.S. Disponivel em <https://www.foodallergy.org/life-with-foodallergies/food-allergy-101/facts-and-statistics>. Acesso em: 19 set. 2018.

FOOD STANDARDS AGENCY (FSA). 14 Allergens. 2014. Disponível em <http://www.food.gov.uk/allergy>. Acesso em: 19 set. 2018.

GUPTA, R.; HOLDFORD, D.; BILAVER, L. The Economic Impact of Childhood Food Allergy in the United States. Jama pediatr., v. 167, n.11, p.1026-1031, 2013.

LUDVIGSSON, J. F. et al. The Oslo definitions for coeliac disease and related terms. Gut, v. 62, p. 43-52, 2013.

MATRICARDI, P. M. et al. EAACI Molecular Allergology User's Guide. Pedriat Allergy Immunol., v. 27, n. 23, p. 1-250, 2016.

OLIVEIRA, A. R. V. et al. Alergia Alimentar: Prevalência Através de Estudos Epidemiológicos. Rev de Ciências da Saúde Nova Esperança, v. 16, n. 1, p. 7-15, 2018.

PÁDUA, I. et al. Alergia alimentar na restauração. Lisboa: DGS, 2016. Disponível em: <https://www.alimentacaosaudavel.dgs.pt/activeapp/wp-

content/files_mf/1464873118AlergiaAlimentarnaRestaurac\%CC\%A7a\%CC\%83o.pdf>. Acesso em: 23 set. 2018.

RADKE, T. J. et al. Restaurant Food Allergy Practices: six selected sites. Morbidity and Mortality Weekly Report, v. 66, n. 15, p. 404-407, 2017.

RUBIO-TAPIA, A. et al. ACG clinical guidelines: diagnosis and management of celiac disease. Am J Gastroenterol, v. 108, n. 5, p. 656-676, 2013.

SDEPANIAN, V. L.; DE MORAES, M. B.; FAGUNDES, N. U. Celiac disease: evolution in knowledge since its original centennial description up to the present day. Arq

Gastroenterol., v. 36, n. 4, p. 244-57, 1999.

SICHERER, S. H.; SAMPSON, H. A. Food Allergy: epidemiology, pathogenesis, diagnosis and treatment. Allergy Clin Immunol., v. 133, p. 291-307, 2014. 
SOLÉ, D. et al. Consenso Brasileiro sobre Alergia Alimentar: 2018 - Parte I Etiopatogenia, clínica e diagnóstico. Arq Asma Alerg Imunol., v. 2, n. 1, p. 7-38, 2018a.

SOLÉ, D. et al. Consenso Brasileiro sobre Alergia Alimentar: 2018 - Parte II Diagnóstico, tratamento e prevenção. Arq Asma Alerg Imunol., v. 2, n. 1, p. 39-82, 2018b. 